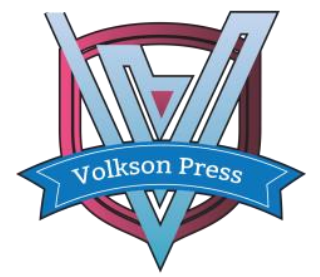

Contents List available at VOLKSON PRESS

Economics \& Management Innovations(EMI)

DOI : http://doi.org/10.26480/icemi.01.2017.162.164

\title{
Study on the Influence of "BigBath" on Cost Stickiness
}

\author{
Wang Congcong1, ${ }^{*}$, Liu Shiping ${ }^{2}$ \\ ${ }^{1}$ Nanjing University of Science and Technology, Nanjing, PR China \\ ${ }^{2}$ Nanjing University of Science and Technology, Nanjing, PR China \\ *353382031@qq.com
}

This is an open access article distributed under the Creative Commons Attribution License, which permits unrestricted use, distribution, and reproduction in any medium, provided the original work is properly cited.

\section{ARTICLE DETAILS}

\section{Article History:}

Received 02 october 2017

Accepted 06 october 2017

Available online 11 october 2017

Keywords:

"bigbath",

earnings

\section{ABSTRACT}

To study the effect of "bigbath" on cost stickiness in earnings management, a multi - regression method was adapted using the data of the A - share listed companies in 2012-2016. The study found that China's listed manufacturing companies do have a strong cost stickiness, and "bigbath" behavior is related to the cost stickiness and will increase the cost stickiness of corporate. Through the study of the effect of earnings management on cost stickiness, the literature of causes of the cost stickiness will be enriched, which helps to explain this black box of the cost management of the enterprise, and provides clues and direction to managers.

\section{Introduction}

The study of cost conduct can help the shareholders interpret the enterprise cost strategy accuratly. However, the traditional theory of cost performance has been influenced by the cost stickiness raised by American scholars Anderson, Banker and Janakiraman (ABJ). Cost stickiness refers to the cost in business volume rise is greater than the decline the volume decreased when the magnitude of decline in matching. This asymmetry has attracted many scholars to study and explore.

When a listed company is facing a loss, the company manager in order to avoid the loss of ST, will produce a specific earnings management behavior "bigbath". This paper uses the data of recent years to study the existence of cost stickiness of manufacturing A-share listed companies in China, and attempts to further study the relationship between the manager of opportunistic earnings management behavior "bigbath" and cost stickiness.

First of all, connecting "bigbath" with the cost stickiness in the same framework, the causes of the cost stickiness literature will be enriched, which has its theoretical significance; secondly, the cost stickiness research can further enhance the company's cost management level, revealing the "black box" of cost management, so that business managers can better carry out real cost management, which has a strong practical significance.

\section{Related theory and research hypothesis}

\subsection{Concept definition}

(1) Cost stickiness

According to the traditional cost theory, the amount of change in costs follows the change in sales. This view is put forward under many assumptions. With the deepening of the extensive research, empirical research has come to the conclusion that it is contrary to the traditional cost hypothesis. ABJ (2003) presents the concept of cost stickiness for the first time: the cost in business volume rise is greater than the decline the volume decreased when the magnitude of decline in matching.

(2) "Bigbath"

"Bigbath" is a more common form of earnings management. The company managers tend to take a specific earnings management behavior "bigbath" when when the deficit is hopeless in this year. That is, the management deliberately raised the cost level, and man-made to create a surplus reserve space for the next year to prepare the company to turn around. This paper, from the perspective of avoiding the withdrawal of the motive, studys relationship between the "bigbath" earnings management behavior and the company's cost stickiness.

\subsection{Research Hypothesis}

ABJ (2003) for the first time confirmed the existence of the cost of stickiness, and clearly put forward the concept of cost sticky. Domestic scholars have studied the cost of stickiness. Sun Feng and Liu Hao (2004) take the data of listed companies in our country as the object of study, testing the existence of cost stickiness. For further research and analysis, we will first test the existence of China's A-share manufacturing companies in the cost of sticky. And this paper presents the hypothesis 1:

H1: China's A-share manufacturing companies exist in the cost stickiness.

As mentioned earlier, China's listed companies for two consecutive years of losses will be special treatment (ST). In this case, the company managers tend to take a specific earnings management behavior "bigbath". During the loss period, the management raised the cost level, and man-made to create a surplus reserve space for the next year to prepare the company to turn around. "Bigbath" mainly includes the provision of asset impairment losses, increasing the company accrual costs and so on. This will allow the company's losses to be further enlarged, the cost of spending increased, making the cost of showing a significant sticky characteristics.For the above reasons, this paper presents the following hypothesis 2 :

H2: Managers have a "bigbath" surplus management motive, the company's cost of sticky will increase.

\section{Study Design}

\subsection{Sample and Data}

Data used in this article are mainly collected from CSMAR database. And this paper uses China's A-share listed manufacturing companies as the research sample, and select data of 2012-2016 according to the following criteria: (1)eliminating enterprises with missing financial accounting data; (2)eliminating the ST companies. Data analysis is completed by STATA and Excel.

\subsection{Variable interpretation}


(1)Explained variable

This paper draws on the measurement method of ABJ (2003), using Ln (SG $\& A_{i, t} / S G \& A_{i, t-1}$ ) as the explained variable. SG\&A in this article is the sum of sales and management costs.

(2)Explanatory variables

This paper use the performance as measure of "bigbath", learning from Jiang Wei and other (2015): If ROE is less than 0 , take 1 , otherwise take 0. Because the existing domestic and foreign literature shows that if the company has a loss, and can not timely turn losses, corporate managers often through the "bigbath" behavior to reduce profits and artificially create surplus reserves, so that the next year to turn around.

\section{(3)Control variables}

In addition to the managerial opportunistic behavior, contract adjustment costs and manager expectations and the like will have an impact on the cost of sticky. To control the impact of these factors, we introduced the asset intensity(AI), labor intensity(EI) and macroeconomic growth(EG) of the three control variables.

\section{Table 3.1 Definition of variables}

\begin{tabular}{l|l}
\hline $\begin{array}{l}\text { Ln }\left(S G \& A_{i}, t / S G \& A_{i}\right. \\
\mathrm{t}-1)\end{array}$ & $\begin{array}{l}\text { taking the logarithm of the quotient of SA\&G this year } \\
\text { and the previous year }\end{array}$ \\
\hline $\begin{array}{l}\mathrm{Ln}\left(\mathrm{Sales}_{\mathrm{i}, \mathrm{t}} / \mathrm{Sales}_{\mathrm{i}},\right. \\
\mathrm{t}-1)\end{array}$ & $\begin{array}{l}\text { taking the logarithm of the quotient of Sales this year and } \\
\text { the previous year }\end{array}$ \\
\hline Dummy & sales drop is 1, otherwise 0 \\
\hline Bigbath & if ROE is less than 0, take 1, otherwise 0. \\
\hline AI & $\begin{array}{l}\text { taking logarithm of the quotient of asset and sales at the } \\
\text { end of the period }\end{array}$ \\
\hline EI & $\begin{array}{l}\text { taking logarithm of the quotient of payable to staff } \\
\text { salaries and sales }\end{array}$ \\
\hline EG & Annual growth rate of GDP \\
\hline
\end{tabular}

\subsection{Testing model}

In order to test the above-mentioned assumptions, two test models are listed here:

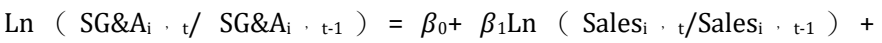
$\beta_{2}{ }^{*}$ Dummy $^{*} \operatorname{Ln}\left(\right.$ Sales $_{i}, t /$ Sales $\left._{i}, t-1\right)+\varepsilon_{i}, t$

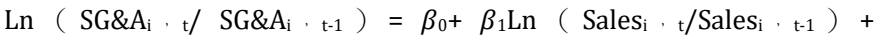
$\beta_{2}{ }^{*}$ Dummy $^{*} \operatorname{Ln}\left(\right.$ Sales $\left._{\mathrm{i}}, \mathrm{t} / \mathrm{Sales}_{\mathrm{i}}, \mathrm{t}-1\right)+\beta_{3}{ }^{*}$ Dummy $^{*} \operatorname{Ln}\left(\right.$ Sales $_{\mathrm{i}}, \mathrm{t} / \mathrm{Sales}_{\mathrm{i}}, \mathrm{t}-1$ ) ${ }^{*}$ Bigbath $+\sum$ Dummy*Ln (Salesi,$t /$ Salesi $\left._{i}, t-1\right){ }^{*}$ Econvaribles $+\varepsilon_{i}, t$ (2)

\section{Empirical Results}

\subsection{Descriptive statistics of variables}

After the relevant selection, 6130 samples were obtained. Table 4.1 Descriptive statistics

\begin{tabular}{|c|c|c|c|c|}
\hline variables & MIN & MAX & AVG & SD \\
\hline $\operatorname{Ln}\left(S G \& A_{i}, t / S G \& A_{i}, t-1\right)$ & -2.38 & 3.81 & 0.16 & 0.31 \\
\hline Ln $\left(\right.$ Sales $_{i, t} /$ Sales $\left._{i, t-1}\right)$ & -3.41 & 4.68 & 0.12 & 0.37 \\
\hline Dummy & 0 & 1 & 0.33 & 0.42 \\
\hline Bigbath & 0 & 1 & 0.10 & 0.31 \\
\hline $\mathrm{AI}$ & -50.21 & 1.24 & -0.11 & 1.09 \\
\hline EI & -32.83 & 14.38 & 0.28 & 0.92 \\
\hline EG & 0.06 & 0.08 & 0.07 & 0.04 \\
\hline
\end{tabular}

From the table can be seen, the maximum and the minimum cost of sales is $3.81,-2.38$, the standard deviation is 0.31 , indicating that the sample business rate of growth rate is not very different. The standard deviation of operating income is 0.37 , which indicates that there is a certain difference in the growth of operating income between sample enterprises. The standard deviation of sales is 0.37 , which indicates that there is a certain difference in the growth of sales between sample enterprises. The descriptive statistics of this section provide preliminary evidence for the study. In order to provide more convincing evidence, empirical study on the existence of corporate cost stickiness is carried out, and on the basis of this, the effect of "bigbath" on the cost of stickiness is analyzed in the following part.

\subsection{Regression analysis}

(1)The result of the existence of stickiness

In order to verify hypothesis 1 , this part uses model (1) to perform multiple regression analysis of the sample, and the results of which are shown in the following table:

Table 4.2 Regression results.

\begin{tabular}{l|l}
\hline variables & Coefficient \\
\hline Constant $\left(\beta_{0}\right)$ & $0.071^{* * *}(0.004)$ \\
\hline Ln $\left(\right.$ Sales $_{\mathrm{i}, \mathrm{t}} /$ Sales $\left._{\mathrm{i}, \mathrm{t}-1}\right)$ & $0.544^{* * *}(0.010)$ \\
\hline${\text { Dummy*Ln }\left(\text { Sales }_{\mathrm{i}, \mathrm{t}} / \text { Sales }_{\mathrm{i}, \mathrm{t}-1}\right)}$ & $-0.292^{* * *}(0.020)$ \\
\hline $\mathrm{R}^{2}$ & 0.385 \\
\hline Adj R $^{2}$ & 0.385 \\
\hline $\mathrm{F}$ & $1,487.074^{* * *}(\mathrm{df}=3 ; 7126)$ \\
\hline
\end{tabular}

It can be seen from the above table, $\beta$ values are significant at $1 \%$ level. According to the above model analysis shows that when the sales revenue increased by $1 \%$, the sales cost increased by $0.544 \%$, and when the sales cost decreased by $1 \%$, the sales cost only reduced by $0.252 \%(0.544$ 0.522). Regression and the expected conclusions are consistent, thus supporting the hypothesis 1 of this article that China's listed companies generally exist the cost stickiness.

(2) The results "bigbath" behavior on the impact of the cost stickiness

Assuming 1 that the sales costs and management costs of our listed companies are sticky, this part carries out the empirical regression test of Hypothesis 2, the results of which are shown in the following table:

\section{Table 4.2 Regression results.}

\begin{tabular}{|c|c|}
\hline variables & Coefficient \\
\hline Constant $\left(\beta_{0}\right)$ & $-0.173^{* * *}(0.064)$ \\
\hline Ln $\left(\right.$ Sales $_{\mathrm{i}, \mathrm{t}} /$ Sales $\left._{\mathrm{i}, \mathrm{t}-1}\right) \quad\left(\beta_{1}\right)$ & $0.680^{* * *}(0.165)$ \\
\hline Dummy $^{*} \operatorname{Ln}\left(\right.$ Sales $_{\mathrm{i}, \mathrm{t}} /$ Sales $_{\mathrm{i}, \mathrm{t}-1}\left(\beta_{2}\right)$ & $-0.343(0.345)$ \\
\hline 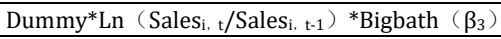 & $-0.163^{* *}(0.067)$ \\
\hline Dummy $^{*} \operatorname{Ln}\left(\right.$ Salesi $_{\mathrm{i}} /$ Salesi, $\left.\mathrm{t}-1\right) * \mathrm{AI}$ & $-0.017(0.021)$ \\
\hline 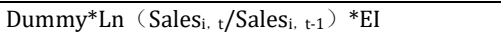 & $0.021(0.015)$ \\
\hline Dummy*Ln $^{*}$ Sales $_{\mathrm{i}, \mathrm{t}} /$ Sales $\left._{\mathrm{i}, \mathrm{t}-1}\right){ }^{*} \mathrm{GDP}$ & $5.480(4.488)$ \\
\hline $\mathrm{R}^{2}$ & 0.410 \\
\hline $\operatorname{Adj~R} R^{2}$ & 0.408 \\
\hline $\mathrm{F}$ & $257.616^{* * *}(\mathrm{df}=19 ; 7055)$ \\
\hline
\end{tabular}

As can be seen from the table above, the $\beta_{3}$ coefficient is -0.163 and is significant at the $5 \%$ confidence level, consistent with the expected results, thus verifying Hypothesis 2. Other conditions are the same, "bgbath" behavior will increase the cost stickiness. When the company's sales decline in the loss, the manager has a "bigbath" motive. They will reduce the current accounting surplus by increasing the current book costs, etc., so that when the company's sales revenue decreased, the cost less, thereby strengthening the cost of stickiness. As can be seen from the above table, the company's asset intensity, labor intensity and economic development level are not significant.

\section{Conclusion}

Cost stickiness caused by managers of opportunism has a strong subjectivist color, from this perspective this article mainly study he relationship between the "bigbath" and the cost stickiness. After the empirical study on the samples of listed manufacturing companies in 2012 and 2016, the following conclusions are drawn:

Cost stickiness prevalence in China's listed companies. the cost in business volume rise is greater than the decline the volume decreased when the magnitude of decline in matching. Managers "bigbath" earnings management behavior will increase the cost of sticky. This article draws on the previous scholars to measure the "bigbath" behavior, found that "wash bath" behavior is positively related to the cost of stickiness.

\section{Acknowledgements}

This paper has greatly benefited from comments from Xiaoma, Xiaodi, Xiaozhang and anonymous reviewers.

\section{References}

[1] Anderson Mark. C. , Rajiv D. Banker, and Surya N. Janakiraman. Are Selling, General, and Administrative Costs Sticky? [J]. Journal of 
Accounting Research, 2003, (41) : $47-63$

[2] Wan Shouyi. Empirical Evidence of Sticky Behavior of Chinese Listed Companies [J]. Auditing and Economic Research, 2012, 27(4) : 7986

[3] Zhang Zhiping, Lin Miao. Earnings Management Motivation and Cost Stickiness [J]. Journal of Hunan University of Commerce,2017,(01):73-79.

[4] Liu E, Liu Lidan, Guo Yingying. Board Governance, Earnings Management and Cost Stickiness [J]. Chinese Certified Public Accountant,2016,(09):41-47+3.
[5] [3]Bi Xiuling, Tan Xuefeng. An Empirical Study on the Cost Adhesion of Costs in Different Industries in China [J]. Friends of Accounting,2015,(09):33-36.

[6] [4]Jiang Wei, Hu Yuming, Lv Zh. Does the accrual earnings management affect the cost of the firm? [J]. Nankai Management Review,2015,(02):83-91.

[7] Wang Dongqing. A Review of the Research on Foreign Cost Stickiness Theory [J]. Finance,2012,(06):27-31.

[8] [5]Su Jie. An Empirical Study on Cost Adhesion of Listed Companies in China [D]. Beijing Forestry University,2014. 